\title{
RECOVERY OF SUCCINIC, FORMIC, AND ACETIC ACID MIXTURE FROM A MODEL FERMENTATION BROTH BY SIMULATED MOVING BED ADSORPTION WITH METHANOL AS DESORBENT
}

Dora Lucía Uribe Santos*, José Antonio Delgado, Vicente Ismael Águeda, Silvia Álvarez Torrellas, Marcos Larriba

Department of Chemical Engineering, Complutense University of Madrid, 28040, Madrid, Spain

*doraurib@ucm.es 
a.)

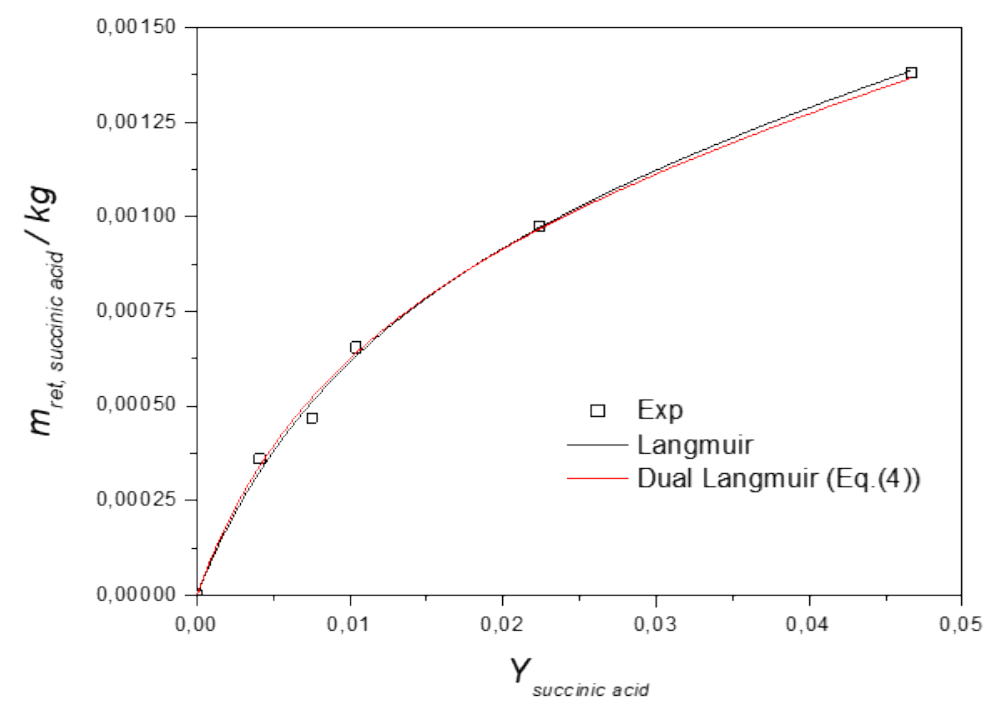

b.)

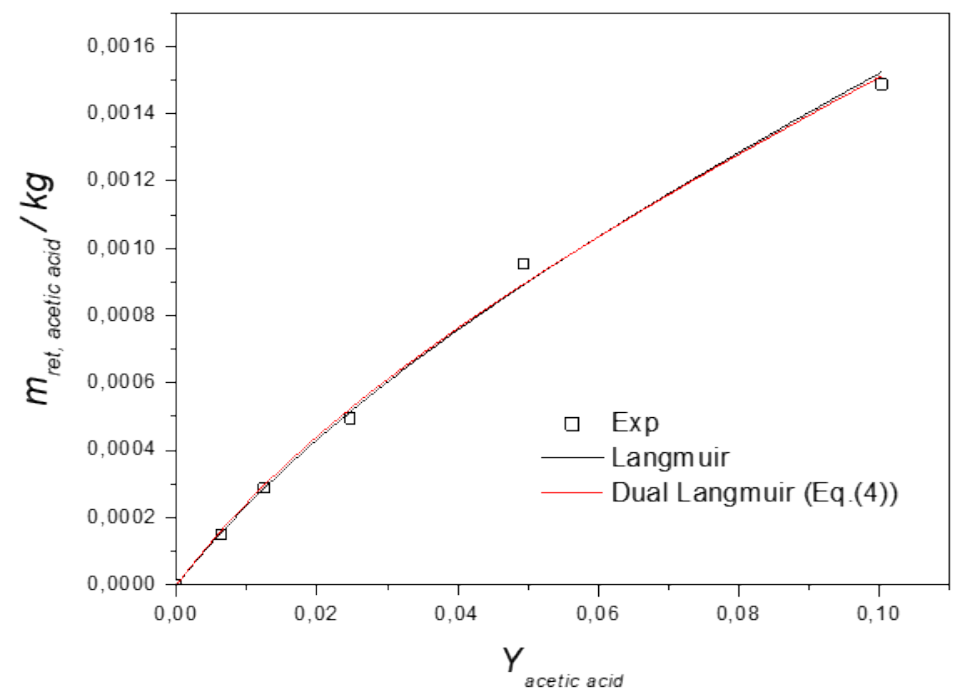

c.)

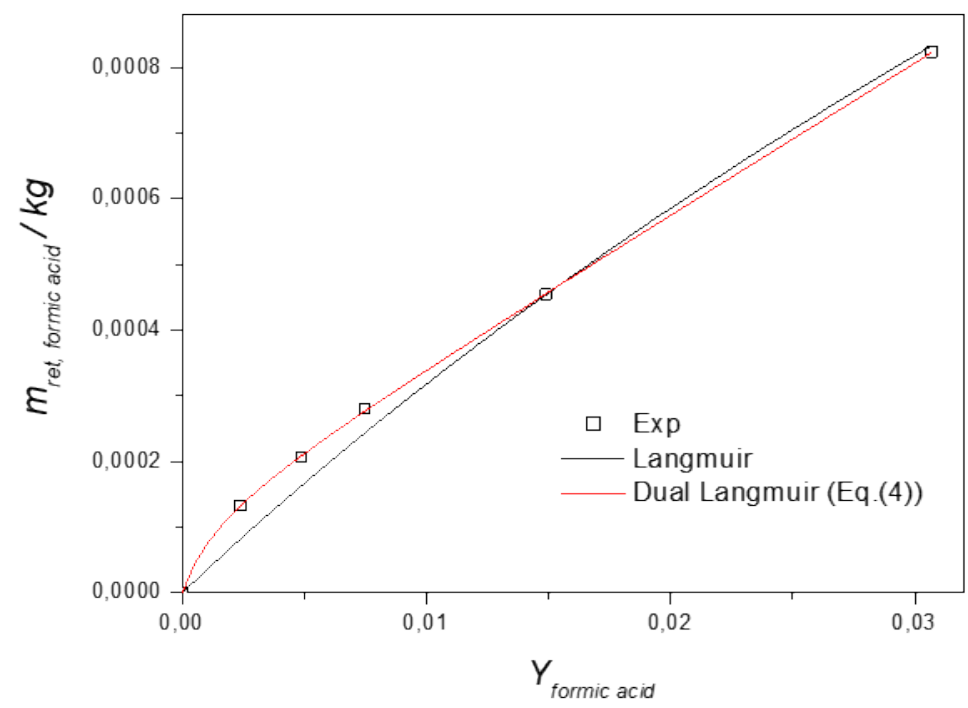

Figure S1. Fit of experimental data for each adsorbate with Langmuir and Dual Langmuir models a.) Succinic acid b.) Acetic acid c.) Formic acid. 
Table S1. Properties of Reillex® 425 resin.

\begin{tabular}{|c|c|}
\hline Property & Value \\
\hline Particle diameter & $650 \mu \mathrm{m}$ \\
\hline Particle density & $640 \mathrm{~kg} \cdot \mathrm{m}^{-3}$ \\
\hline Particle porosity & 0.46 \\
\hline Moisture content & $50-75 \%$ \\
\hline
\end{tabular}

Table S2. Parameters of Langmuir and Dual Langmuir isotherms.

\begin{tabular}{|c|c|c|c|c|c|}
\hline \multicolumn{6}{|l|}{ Dual Langmuir model } \\
\hline Solute & $\begin{array}{c}a_{1}, \\
\mathrm{~m}^{3} \mathrm{~kg}_{\mathrm{resin}}{ }^{-1}\end{array}$ & $\begin{array}{c}\mathrm{a}_{2}, \\
\mathrm{~m}^{3} \mathrm{~kg}_{\mathrm{resin}}^{-1}\end{array}$ & $\begin{array}{c}b_{1}, \\
\mathrm{~m}^{3} \mathrm{~kg}^{-1}\end{array}$ & $\begin{array}{c}b_{2}, \\
\mathrm{~m}^{3} \mathrm{~kg}^{-1}\end{array}$ & $r^{2}$ \\
\hline Succinic acid & 0.028 & 0.004 & 0.082 & 0.822 & 0.996 \\
\hline Acetic acid & 0.004 & 0.0005 & 0.022 & 0.022 & 0.996 \\
\hline Formic acid & 0.004 & 0.024 & 0 & 0.642 & 0.999 \\
\hline Langmuir model & 0.027 & - & 0.076 & - & 0.997 \\
\hline Succinic acid & 0.005 & - & 0.019 & - & 0.996 \\
\hline Acetic acid & 0.007 & - & 0.014 & - & 0.986 \\
\hline Formic acid & 0.076 & & \\
\hline
\end{tabular}

